\title{
Análise de narrativas praxeológicas de conexões entre aritmética e álgebra
}

\author{
Analysis of Praxeological Narratives of Connections between Arithmetic \\ and Algebra
}

\author{
José Carlos de Souza Pereira ${ }^{1}$ \\ Francisco Hermes Santos da Silva² \\ José Messildo Viana Nunes ${ }^{3}$
}

\section{Resumo}

Este artigo é produto de uma pesquisa narrativa autobiográfica que expõe a análise das praxeologias do primeiro autor, no contexto do seu desenvolvimento profissional, como professor de matemática. O foco da análise recai sobre os diversos conflitos praxeológicos que esse vivenciou durante a elaboração e aplicação, em sala de aula, de uma proposta didática para ensinar operações polinomiais na sétima série (oitavo ano) do Ensino Fundamental. Para analisar suas próprias praxeologias a partir da proposta didática que elaborou, esse assumiu a Teoria Antropológica do Didático (TAD) de Yves Chevallard como referencial teórico principal. Os resultados apontam que as relações pessoais do primeiro autor envolveram tipos de objetos ostensivos e não ostensivos, e tipos de tarefas e técnicas presentes ou não na proposta didática que ele elaborou, revelando as praxeologias passadas e presentes, que compunham os diversos momentos de seu desenvolvimento profissional como professor de matemática.

Palavras-chave: Narrativa Autobiográfica; Aritmética e Álgebra; Teoria Antropológica do Didático; Objetos Ostensivos e Não Ostensivos; Análise Praxeológica.

\begin{abstract}
This article is the product of an autobiographical narrative study, which shows an analysis of the praxeologies of the first author, in the context of his professional development as a mathematics teacher. The focus of the analysis is on the various praxeological conflicts that the author experienced during the elaboration and application in the classroom of a didactical proposal for the teaching of polynomial operations in the 7th grade of primary school. In order to analyse his own praxeologies using the didactical proposal he elaborated, the author used Yves Chevallard's Anthropological Theory of the Didactical (ATD) as the main theoretical reference. The results demonstrated that the personal relations of the first author involved ostensive and non-ostensive types of objects and different tasks and techniques that were either present or not in the didactical proposal he elaborated, revealing past and present praxeologies which composed several different moments of his professional development as a mathematics teacher.
\end{abstract}

Keywords: Autobiographical Narrative; Arithmetic and Algebra; Anthropological Theory of the Didactical; Ostensive and Non-Ostensive Objects; Praxeological Analysis.

\footnotetext{
${ }^{1}$ Universidade Federal do Pará | jsouzaper@gmail.com

${ }^{2}$ Universidade Federal do Pará | fhermes@ufpa.br

${ }^{3}$ Universidade Federal do Pará | messildo@ufpa.br
} 


\section{Introdução}

As premissas da pesquisa, aqui narrada, surgiram com o curso de Especialização em Educação Matemática, promovido pelo Núcleo Pedagógico de Apoio ao Desenvolvimento Científico (NPADC), da Universidade Federal do Pará (UFPA). O NPADC, em 2009, adquiriu o status de Instituto de Educação Matemática e Científica - IEMCl, atuando nos níveis de graduação, especialização, mestrado e doutorado.

Inicio esta narrativa resgatando memórias do curso de especialização, mais precisamente, da disciplina Tendências Metodológicas em Educação Matemática que cursei na referida pós-graduação. Durante as aulas dessa disciplina, várias abordagens metodológicas e didáticas foram apresentadas pelo professor ministrante. Uma dessas abordagens tratava da dificuldade existente quando se ensina operações com polinômios na sétima séria (oitavo ano) do Ensino Fundamental. Além disso, o professor ministrante da disciplina expôs uma ideia que considerei viável para aplicação em sala de aula. Isso me motivou juntamente com uma colega de curso na idealização de uma proposta didática para ensinar adição, subtração, multiplicação e divisão de polinômios no oitavo ano do Ensino Fundamental. Essa proposta consiste em associar o valor posicional dos algarismos indo-arábicos, no sistema de numeração decimal, por meio uma expressão algébrica, considerando a base dez igual a uma letra, por exemplo, $x=10$. Essa ideia adquiriu maior consistência quando o professor formador a fundamentou na Teoria da Aprendizagem Significativa de Ausubel et al. (1980), na qual os conhecimentos prévios dos alunos devem ser a base para subsequentes aprendizagens.

Em comum acordo com minha colega de curso da especialização, recorremos ao livro de Floriani (2000), que esboça uma compreensão, associando o ensino de polinômios aos sistemas de numeração posicional, tanto na base dez como para quaisquer bases. Já para a teoria ausubeliana, adotamos Ausubel et al. (1980).

O aprofundamento da leitura e a discussão dos referidos autores nos permitiu correlacionar a Teoria da Aprendizagem Significativa às ideias didáticas contidas no livro de Floriani. Assim, produzimos a monografia intitulada: "Aprendizagem Significativa - das Operações Aritméticas às Operações Algébricas: o tratamento das operações algébricas a partir das operações aritméticas como conhecimento prévio".

A pesquisa desenvolvida na especialização possibilitou-me construir uma proposta de pesquisa para dar continuidade e aprofundar os estudos em nível de mestrado sobre a conexão entre aritmética e álgebra, perpassando pelo ensino das operações com polinômios, a partir do oitavo ano do Ensino Fundamental.

Ao ingressar no mestrado, passei a fazer parte do Grupo de Pesquisas em Didática da Matemática (GEDIM), assim, tomei ciência de teorias que compõem a Didática da Matemática, entre elas, a Teoria Antropológica do Didático (TAD) de Yves Chevallard. Deste modo, inseri minha proposta de pesquisa neste campo teórico.

Escolhi a TAD porque ela me possibilitou analisar as minhas próprias praxeologias como professor de Matemática no que se refere à elaboração e aplicação da proposta didática que consta na monografia de Carvalho e Pereira (2009), em termos de tipos de tarefas Ti, técnica $\tau$, tecnologia $\theta$ e teoria $\Theta$ (CHEVALLARD, 1999). Além disso, o estudo TAD, no GEDIM, conduziu-me a conectar essa teoria à pesquisa narrativa (FREITAS; FIORENTINI, 2007; SAVELI, 2006; GONÇALVES, 2011).

Durante o estudo da obra de Floriani (2000) para elaborar a proposta didática, confrontei-me com as minhas limitações como professor de Matemática no tratamento das 
operações aritméticas e operações com polinômios. Entre essas limitações, estava o meu desconhecimento sobre os objetos matemáticos ostensivos e não ostensivos, e das praxeologias, que podem ser, resumidamente, descritas por tarefas, tipos de tarefas, técnicas, tecnologias e teorias, assim anunciadas em Chevallard e Bosch (1999).

A ostensividade e a não ostensividade dos objetos matemáticos são componentes anunciados por Chevallard e Bosch (1999), que contribuem para uma compreensão dos significados que tem a manipulação ostensiva da álgebra no Ensino Fundamental.

Dessa forma, objetivo principal deste artigo é revelar as possíveis conexões entre aritmética e álgebra que determinaram as minhas praxeologias durante a ampliação didática desenvolvida por mim, para ensinar adição, subtração, multiplicação e divisão de polinômios, no oitavo ano do Ensino Fundamental. Assim, para alcançar esse objetivo, as noções de Universo Cognitivo4 e Equipamento Praxeológico5 da pessoa x (CHEVALLARD, 2009) como professor de Matemática está em jogo.

\section{Aspectos Metodológicos}

O desenvolvimento metodológico inicial consta de pesquisa bibliográfica (RAMPAZZO, 2002; SEVERINO, 2007), com o objetivo de realizar um breve estudo do contexto histórico do desenvolvimento de alguns sistemas de numeração, precursores do sistema de numeração indo-arábico, e do uso da aritmética e da álgebra por algumas civilizações. Após essa verificação, prossegui identificando as possíveis conexões entre aritmética e álgebra anunciadas em algumas obras, que explicitam as interlocuções existentes entre o valor posicional dos algarismos indo-arábicos e suas escritas polinomiais na potência de base dez.

Para que eu interligasse os meus estudos constantes na monografia de Carvalho e Pereira (2009) com a pesquisa bibliográfica, assumi a pesquisa narrativa como norteadora principal do meu discurso. Assim, associo-me ao que diz Aragão (2011, p. 14), enfatizando que: "Tem sido cada vez mais frequente o uso de investigações narrativas em estudos e pesquisas sobre a experiência humana. De forma tal que, posso dizer, esta já tem uma longa história intelectual e acadêmica dentro e fora da educação [...]". Deste modo, percebo a pesquisa narrativa imbricada na minha prática docente como professor de Matemática. Além disso, serve como exemplo do ato de narrar.

Os instrumentos de coletas de dados da pesquisa narrativa são vários, entres estes estão: "[...] registros de campos, anotações em diários, entrevistas semi ou não estruturadas, história de vida (orais ou escritas), observações diretas, em situações de contar histórias, por meio de cartas, autobiografias, documentos diversos [...]" (GONÇALVES, 2011, p. 64-65). Concernente a esta pesquisa, a coleta de dados primária se deu na época do Curso de Especialização em Educação Matemática, no qual cursei e conclui no período de 2008 a 2009.

Para esta pesquisa, o sujeito é uno, ou seja, eu mesmo. O instrumento de análise são os meus estudos que constam na monografia de Carvalho e Pereira (2009). Deste modo, o

\footnotetext{
${ }^{4} U C(x)=\{(0, R(x ; 0)) / R(x ; 0) \cdot \cdot \cdot \cdot\}$ : dinâmicas cognitivas de $x$ e suas relações pessoais com objetos matemáticos (CHEVALALRD, 2009).

${ }^{5}$ EP(x): conjunto de praxeologia que a pessoa possui ou estar equipada (CHEVALLARD, 2009).
} 
texto narrativo autobiográfico se estabelece. Desenvolvo-o estabelecendo "diálogos" com várias obras e seus autores, e na perspectiva da Teoria Antropológica do Didático (TAD). A TAD será mediada sob a insígnia de pesquisadores que interpretaram ou interpretam essa teoria, assim como, do seu idealizador, Yves Chevallard.

A narrativa autobiográfica possibilitou-me relatar sobre minhas praxeologias antes e depois do Curso de Especialização, assim como do meu desenvolvimento profissional referente ao mesmo período. Isso se interliga ao que Freitas e Fiorentini (2007) referenciam quando mencionam as ideias de Clandinin (1993) sobre a narrativa do professor.

[...] o professor, ao narrar de maneira reflexiva suas experiências aos outros, aprende e ensina. Aprende, porque, ao narrar, organiza suas ideias, sistematiza suas experiências, produz sentidos a elas e, portanto, novos aprendizados para si. Ensina, porque o outro, diante das narrativas e dos saberes de experiência do colega, pode (re)significar seus próprios saberes e experiências [...] (FREITAS; FIORENTINI, 2007, p. 66).

Para Saveli (2006, p. 95): "[...] O exame de narrativas memorialísticas, autobiografias, diários vem se constituindo como uma tendência metodológica no contexto da pesquisa [...]". Bueno (2002, p. 21) também considera o método autobiográfico importante para as pesquisas educacionais, porque "[...] é importante lembrar que as abordagens autobiográficas na área da educação têm sido notadamente utilizadas na formação continuada de professores".

Para Bastos e Colla (2004, p. 466), "[...] Reconstruir o vivido permite esclarecer, em parte, o enfrentamento dos desafios epistemológicos da atividade docente, em que as motivações de vida estão intimamente ligadas [...]". Pelo exposto, o meu desenvolvimento profissional na carreira docente possui vínculos subjetivos, íntimos e pessoais. Consequentemente, esses vínculos servem de elementos rememorativos para a narrativa autobiográfica que assumi nesta pesquisa.

\section{Características da Pesquisa}

A pesquisa aqui relatada foi caracterizada por meio de três aspectos: 1) Da revisão sobre os processos de ensino e aprendizagem da álgebra; 2) Breve estudo histórico sobre a numeração decimal; e 3) Um estudo epistemológico da adição, subtração, multiplicação e divisão de polinômios.

No primeiro aspecto, retomo as concepções anunciadas por Usiskin (1995). Além disso, verifico, nas pesquisas de Cruz (2005), Carvalho (2007) e Sousa (2007), as implicações dessas concepções nos processos de ensino e aprendizagem da álgebra. Em aproximação com as concepções de Usiskin, Pilar Bolea $(2003$, p. 65) considera que o modelo dominante da álgebra escolar é o da aritmética generalizada.

Evidenciei que a concepção da álgebra como aritmética generalizada é a que predomina no processo de ensino da álgebra elementar, conforme revela a pesquisa de Pilar Bolea (2003) e de Sousa (2007). Essa concepção assume um papel predominante na minha prática docente como professor de Matemática. Além disso, pressuponho que o significado da álgebra no currículo oficial do ensino básico brasileiro apresenta características próximas das de outros países, entre estes, a França. Assim, remeto-me a 
Chevallard (1994), ao afirmar que a palavra álgebra recebe uma significação quando se trata do ensino desta no programa oficial da França. Segundo o próprio autor,

[...] O rótulo "álgebra" tem muito tempo jogado na França um papel estruturante essencial no corpus da matemática ensinada, em conjunto com "aritmética" e "geometria" (deixando aqui de lado a análise matemática), no âmbito de uma estrutura duplamente oposta [...] (CHEVALLARD, 1994, p. 181, tradução nossa, grifos do autor).

A estrutura duplamente oposta, anunciada pelo autor, considera a Matemática sob duas vertentes: 1) Geometria (espaço) e 2) Não geometria (número) - Aritmética e Álgebra.

Lendo a pesquisa de Keppke (2007), verifiquei que ela exibe um estudo sobre a "Álgebra nos Currículos do Ensino Fundamental". Nesse estudo, ele analisa alguns documentos que nortearam ou norteiam o ensino da álgebra no Brasil, entre os quais estão: "os Guias Curriculares (1970), a proposta Curricular para o Ensino de $1^{\circ}$ Grau (1980) e os Parâmetros Curriculares Nacionais (1a edição, anos 1990)" (Ibidem, p. 40). Desses três documentos, os Parâmetros Curriculares Nacionais é o mais recente e ainda orienta o ensino de Matemática na Educação Básica. Por conseguinte, Keppke (2007, p. 49) expõe que:

No Brasil, principalmente a partir da década de 1950, podemos observar muitas iniciativas de mudança curricular as quais, em sua maior parte, partiram do governo [...]. Segundo esse autor, [...] o ensino da Álgebra sofreu um processo de simplificação, para atender a uma demanda por ensino que atingia, de fato, todas as classes sociais. A Álgebra passou a ser, com a industrialização, exigência básica para a formação de pessoas de qualquer camada social [...].

Assim, via-se, no ensino da Álgebra, o propulsor de ascensão social, mas, de fato, isso não aconteceu, pois essa mesma Álgebra, tornou-se uma barreira para essa ascensão social.

O segundo aspecto que caracteriza esta pesquisa abre uma breve discussão histórica sobre o sistema de numeração decimal, no qual residem várias implicações epistemológicas que estão atreladas a outros sistemas de numeração.

Para este fim, li a dissertação de Almeida (2007), que mostra a influência de alguns sistemas de numeração, apontados, por ele, como precursores do nosso sistema de numeração posicional de base dez. Esse mesmo autor atribuiu serem relevantes para sua pesquisa os Sistemas Babilônico, Ático, Hindu, Egípcio e Romano. O autor detalhou cada um desses sistemas de numeração, algo que não farei aqui, mas versarei de forma breve sobre eles.

Os babilônios adotaram várias bases para suas práticas numéricas, contudo, a base sexagesimal foi a mais importante. A referência dessa base recai sobre os sumérios. Segundo Ifrah (1997a, p. 162): "[...] Em vez de contar por dezenas, centenas e milhares, os sumérios tinham preferido optar pela base 60, agrupando assim os seres e as coisas por sessentenas e potências de sessenta".

No sistema de numeração babilônico, as operações aritméticas estiveram presentes e permitiram o desenvolvimento de técnicas que possibilitaram a elaboração de tabelas multiplicativas e listas de recíprocos (GALVÃO, 2008). 
A civilização egípcia idealizou um sistema de numeração caracterizado pela aditividade e associado à ideia de base dez. Esse sistema de numeração possuía mais símbolos que o sistema de numeração babilônico.

Aproximando os algarismos egípcios com a potência de base dez, temos: unidade $($ traço vertical $)=10^{0}$; dezena (sinal em forma de " $U$ " invertido $)=10^{1}$; centena (espiral) $=10^{2}$; milhar (flor de lótus) $=10^{3}$; dezena de mil (dedo levantado e ligeiramente inclinado) $=10^{4}$; centena de mil (rã ou girino) $=10^{5}$ e milhão (homem ajoelhado erguendo as mãos para o céu) $=10^{6}$. A aproximação que fiz serve para mostrar que os egípcios constituíram um sistema de numeração com ideias semelhantes ao do nosso sistema de numeração decimal.

Quando a escrita egípcia passou da hieroglífica para a hierática, os algarismos hieroglíficos também foram adaptados para essa nova escrita. O Papiro de Rhind está grafado em caracteres hieráticos (IFRAH, 1997a). Dessa forma, o Papiro de Rhind é uma prova material da escrita hierática egípcia.

As informações que conhecemos sobre a matemática egípcia encontram-se em três papiros: papiro de Rhind ou de Ahmes, papiro de Moscou e papiro do Cairo (GALVÃO, 2008, p. 72-73). O estudo desses papiros revelou que, no sistema de numeração egípcio, a aritmética predominava nas práticas de cálculos dos escribas egípcios. Porém, a álgebra também aparece, principalmente, em problemas algébricos (GALVÃO, 2008, p. 73).

A numeração grega antiga, como o sistema numérico ático, possuía característica aditiva e uma grafia muito interessante. De certa forma, essa representação dos números áticos, quando associados ao nosso sistema de numeração usual, expressa uma disposição aditiva de ordens e classes. Alguns símbolos da numeração ática estavam associados à escrita grega desses números, por exemplo,

[...] os números $10,10^{2}, 10^{3}$ e $10^{4}$, as quais são, respectivamente $\Delta, H, X$ e $M$. Estes quatro símbolos derivaram das iniciais dos nomes gregos dos números que representam, a saber, deka (dez), hekaton (cem), chilioi (mil), e myrioi (dez mil) (ALMEIDA, 2007, p. 52).

Ao estudar um pouco mais sobre a evolução histórica da representação dos números romanos, compreendi que eles sofreram adaptações, ao longo do tempo, no contexto das práticas sociais da civilização romana. Assim, a limitação operatória desse sistema fez com que esses algarismos passassem a ter uma função de indicar quantidade. Ilustro isso com o número: $M D L X X V=1 \cdot 10^{3}+5 \cdot 10^{2}+5 \cdot 10^{1}+1 \cdot 10^{1}+1 \cdot 10^{1}+5 \cdot 10^{0}=1 \cdot 10^{3}+5 \cdot 10^{2}+(5+1+$ 1) $\cdot 10^{1}+5 \cdot 10^{0}=1 \cdot 10^{3}+5 \cdot 10^{2}+7 \cdot 10^{1}+5 \cdot 10^{0}=1$ unidade de milhar +5 centenas +7 dezenas +5 unidades $=1575$.

Agora, faço um breve relato da história da numeração Hindu-Árabe. Duas civilizações que impulsionaram o conhecimento aritmético e algébrico. Sem dúvida, o desenvolvimento da matemática ocidental perpassa pelos estudos matemáticos dessas duas civilizações. A começar pelos algarismos denominados de indo-arábicos: 1, 2, 3, 4, 5, 6, 7, 8, 9 e 0.

A numeração falada da civilização indiana, mais precisamente a língua sânscrita, contribuiu para o que hoje conhecemos como escrita por extenso dos numerais. Na língua sânscrita, os algarismos das nove unidades simples eram pronunciados: eka, dvi, tri, catur, pañca, sat, sapta, asta, nava (IFRAH, 2005, p. 267). 
A solução que os astrônomos indianos encontraram para indicar a ideia do zero foi recorrer à palavra sânscrita šhûnya $\sigma^{6}$ que significa "vazio" e, por extensão, "zero" (IFRAH, 1997b, p. 110). Desse modo, para diferenciar, por exemplo, 42 de 402. Os hindus pronunciavam 402: "dvi śūnya catur" ("DOIS. VAZIO. QUATRO"). Usando a palavra "śūnya", os hindus tinham constituído o algarismo zero, mas apenas de forma oral.

Os árabes recopiaram, inicialmente, "a numeração posicional e os métodos de cálculos originários da índia" (IFRAH, 2005, p. 299). Esses algarismos passaram por modificações na cultura árabe antes de assumirem a forma como os conhecemos atualmente. Além disso, a primeira introdução desses algarismos na cultura ocidental cristã ocorreu na Europa (final do século X), por meio do monge francês Gerbert d'Aurillac (IFRAH, 1997b).

O estágio final da grafia numérica Hindu-Árabe, tal como conhecemos hoje na cultura ocidental, é consolidado por volta do século XIII e XIV. Após isso, o que se verifica é o aprimoramento tipográfico proporcionado pela invenção da imprensa por Gutenberg (IFRAH, 2005). Assim, os algarismos indo-arábicos atingiram a grafia numérica atual, que ensinamos nas instituições escolares, por meio do sistema de numeração decimal.

O terceiro aspecto desta pesquisa volta-se para uma compreensão epistemológica ao tratamento da adição, subtração, multiplicação e divisão polinomial. Nessa compreensão epistemológica, proponho um modelo epistemológico alternativo ${ }^{7}$ (este modelo será explicitado mais à frente) para o ensino dessas operações no Ensino Fundamental.

As ideias deste modelo epistemológico alternativo estão imbricadas no sistema de numeração posicional de base dez e em bases quaisquer. Assim, podemos compor um sistema de numeração posicional a partir da escolha de um número $b$ que sirva de base (EVES, 2004). A nossa referência para outras bases é a base dez do sistema de numeração decimal. Adotei, neste estudo, a representação $N_{(b)}$, na qual o indicativo em que base 0 número $N$ está representado é (b). Desse modo, quando tivermos $b=2,3$, 5; podemos representar o número $N$, como segue:

- Base 2: $N=a_{n} b^{n}+a_{n-1} b^{n-1}+\ldots+a_{2} b^{2}+a_{1} b^{1}+a_{0} ; 0 \leq a_{i}<b, \quad i=0,1,2$, $3, \ldots, n ; a_{i} \in\{0,7\}$ e $b=2$;

- Base 3: $N=a_{n} b^{n}+a_{n-1} b^{n-1}+\ldots+a_{2} b^{2}+a_{1} b^{1}+a_{0} ; 0 \leq a_{i}<b, i=0,1,2,3, \ldots$, $n ; a_{i} \in\{0,7,2\}$ e $b=3$;

- Base 5: $N=a_{n} b^{n}+a_{n-1} b^{n-1}+\ldots+a_{2} b^{2}+a_{1} b^{1}+a_{0} ; 0 \leq a_{i}<b, i=0,1,2,3, \ldots$, $n ; a_{i} \in\{0,7,2,3,4\}$ e $b=5$;

Em relação à base dez, as obras De Maio (2011, 2009), Zuin (2005), Floriani (2000), Crantz (1949), Roxo et al. (1948), Carles (1927) e Wechelun (1562) revelam compreensões epistemológicas que conectam aritmética e álgebra, conforme proponho no modelo epistemológico que elaborei.

Roxo et al. (1948) assim expõem a representação de um número $N$ no sistema de numeração decimal:

\footnotetext{
${ }^{6}$ Em Ifrah (2005, p. 270), está grafado śūnya, grafia que usarei neste texto.

7 Segundo Delgado (2006), o modelo epistemológico alternativo é um modelo de organização matemática e didática proposto, objetivando-se melhorar a compreensão dos objetos matemáticos tratados nesse modelo.
} 
No sistema de base 10, todo número $\mathrm{N}$ pode ser escrito sob a forma $\mathrm{N}=$ $u+d \cdot 10+c \cdot 10^{2}+\ldots$ onde $u, d, c$, etc. indicam respectivamente os algarismos das unidades, dezenas, centenas, etc. Do mesmo modo, no sistema de base $b$, o número $N$ poderá ser posto sob a forma de soma ordenada segundo as potências de $b$, do seguinte modo $N=\alpha+\beta . b+\gamma$ $b^{2}$ onde $\alpha, \beta$, $\gamma$, etc. indicam números menores que $b[\ldots]$ (ROXO et al., 1948, p. 64).

Com base na escrita dos números $N$, pertencentes ao sistema de numeração decimal, conforme se encontra em Roxo et al. (1948), proponho a escrita polinomial abaixo para os números inteiros positivos $N_{7}$ e $N_{2}$ no sistema de numeração decimal:

$$
\begin{aligned}
& \quad N_{1}=x_{0}+x_{1} \cdot 10+x_{2} \cdot 10^{2}+x_{3} \cdot 10^{3}+\ldots+x_{n} \cdot 10^{n}, 0 \leq x_{i}<10, i=0,1, \ldots, n \text { e } \\
& N_{2}=y_{0}+y_{1} \cdot 10+y_{2} \cdot 10^{2}+y_{3} \cdot 10^{3}+\ldots+y_{n} \cdot 10^{n}, 0 \leq y_{i}<10, i=0,1, \ldots, n .
\end{aligned}
$$

Doutro modo, se a escrita polinomial de $N_{1}$ e $N_{2}$ não for na base dez, essa modelização ${ }^{8}$ também é válida. Por exemplo, se tenho $N_{1}=2.7^{2}+5.7+1$ e $N_{2}=3.7^{2}+1.7+4$, então $N_{1} \times N_{2}=\left(2.7^{2}+5.7+1\right)\left(3.7^{2}+1.7+4\right)=1.7^{5}+1.7^{4}+5.7^{3}+5.7^{2}+0.7+4=115504(7)$.

Se a escrita polinomial de $N_{1}$ e $N_{2}$ for representada pelos polinômios $2 x^{2}+5 x+1$ e $3 x^{2}+$ $x+4$, a tarefa consiste em: Multiplicar $2 x^{2}+5 x+1$ por $3 x^{2}+x+4$. Logo, o resultado que se obtém é o polinômio $6 x^{4}+17 x^{3}+16 x^{2}+21 x+4$. Notam-se, nesse polinômio, que os coeficientes dos termos algébricos são quase todos diferentes dos que aparecem no resultado da multiplicação da escrita polinomial dos números $N_{7}$ e $N_{2}$. Isso ocorreu porque, na multiplicação polinomial, o processo resolutivo não exige transporte de ordem. Entretanto, do polinômio $6 x^{4}+17 x^{3}+16 x^{2}+21 x+4$, chega-se ao resultado da multiplicação dos números $N_{1}$ e $N_{2}$. Para isso, é suficiente tornar $x=7$ e proceder com os ajustes dos coeficientes e dos expoentes de $x$ pelo produto de potência de mesma base.

O procedimento descrito para a base sete é valido para quaisquer sistemas de numeração posicional de base não decimal, desde que se obedeça às particularidades das bases numéricas que constituem esses sistemas. $O$ passo posterior é compreender como os algoritmos das operações aritméticas fundamentais funcionam nesses sistemas de numeração posicional e, também, sua extensão para a álgebra. Nesse sentido, a ostensividade e a não ostensividade dos objetos matemáticos cumprem um papel decisivo e esclarecedor na compreensão epistemológica das operações algébricas, principalmente, na adição, subtração, multiplicação e divisão de polinômios.

Recorri a Chevallard e Bosch (1999) para uma melhor compreensão sobre objetos ostensivos e não ostensivos, que, segundo eles, esses objetos são dicotômicos devido à natureza e à função desses objetos na atividade matemática. Compreenda-se que ostensivo vem do termo em latim ostendere, significando algo que se mostra, apresenta-se insistentemente, possui natureza sensível, certa materialidade e, por isso, tal objeto pode ser apreendido pelo sujeito por constituir uma realidade perceptível (CHEVALLARD; BOSCH, 1999). Portanto,

\footnotetext{
${ }^{8}$ [...] a noção de modelização permite dar conta da atividade matemática. Esta noção é estabelecida sobre uma distinção clássica: a do sistema (para estudar) e os seus modelos (que permitem o estudo [...] (CHEVALLARD, 1990, p. 5, tradução nossa).
} 
[...] um objeto ostensivo é um objeto material qualquer tal como os sons (entre os quais as palavras de uma língua) os grafismos (entre os quais os grafemas que permitem a escrita das línguas naturais ou construídas das línguas formais) e os gestos. Os objetos não ostensivos são então todos os objetos como as ideias, as intuições ou os conceitos, existentes institucionalmente, no sentido de que Ihes são atribuídas existências, sem poder ser vistos, ditos, mostrados, percebidos por si mesmo. Esses objetos podem ser evocados ou invocados pela manipulação adequada de certos objetos ostensivos associados (palavras, frases, grafismos, escritas, gestos ou um longo discurso) [...] (CHEVALLARD; BOSCH, 1999, p. 10, tradução nossa).

Chevallard e Bosch (1999) exemplificam a manipulação dos ostensivos e dos não ostensivos por meio de uma adição de polinômios. Esse exemplo conecta o modelo epistemológico alternativo que proponho e a análise que exponho nesta pesquisa.

[...] a existência para mim, segundo uma relação idônea, do objeto não ostensivo "adição de polinômios" pode parecer como uma condição para que eu escreva: $\left(x^{3}+x+1\right)+\left(x^{2}+4 x-2\right)=x^{3}+x^{2}+5 x-1$. Do mesmo modo, o fato que, contrariamente ao hábito gerado pelo ensino secundário, eu escrevo $\left(x^{3}+x+1\right)+\left(x^{2}+4 x-2\right)=-1+5 x+x^{2}(1+x)$ invocará a hipótese que existe para mim certos objetos não ostensivos que condicionam a tarefa realizada, motivando-a, regulando o seu desenvolvimento e propondo um critério de parada da transformação operada - poderá se tratar, neste caso, do objeto não ostensivo "desenvolvimento limitado de ordem 1", por exemplo [...] (CHEVALLARD; BOSCH, 1999, p. 12, tradução nossa).

A dialética que existe na manipulação dos ostensivos e dos não ostensivos está posta na resolução da tarefa - resolver: $\left(x^{3}+x+1\right)+\left(x^{2}+4 x-2\right)$ - que é uma tarefa $t_{0}$ pertencente a tipo de tarefas $T\left(t_{0} \in T\right)^{9}$. Assim, prosseguindo com essa dialética, infiro que $T$ é: resolver as operações com polinômios. Por conseguinte, a força dessa dialética, segundo Almouloud (2007), está na atividade matemática.

Na análise da atividade matemática, a dialética ostensivo/não ostensivo é, geralmente, concebida em termos de signos e de significação: os objetos ostensivos são signos de objetos não ostensivos que constituem o sentido ou a significação. A função semiótica dos ostensivos, sua capacidade de produzir um sentido ou significado, não pode ser separada de sua função instrumental, de sua capacidade de integrar-se nas manipulações técnicas, tecnológicas e teóricas. Queremos dizer que os ostensivos são

\footnotetext{
9 [...] podemos entender a Tarefa (t), que está sempre relacionada a um Tipo de tarefas (T), como toda ação singular, particular, específica de um fazer que se expressa por um verbo, como: encontrar a fração reduzida; fatorar o polinômio; simplificar a expressão algébrica; encontrar a equação da reta tangente à curva no ponto $P$ [...] Já o Tipo de tarefas (T), é um conjunto de ações do mesmo tipo, ou seja, é uma classe de tarefas com características comuns, como: simplificar expressões algébricas; encontrar equações de retas tangentes a uma curva em um dado ponto $P$; determinar o quociente entre dois números dados etc., isto é $T=\left\{t_{1}, t_{2}, t_{3}, t_{4}, \ldots, t_{n}\right)$ No quadro abaixo, exemplificamos alguns tipos de tarefas e suas possíveis tarefas associadas (ANDRADE, 2012, p. 18).
} 
ferramentas materiais para a ação nas organizações matemáticas. As duas funções, semiótica e instrumental, coabitam (ALMOULOUD, 2007, p. 121).

A técnica $\tau$ e a tecnologia $\theta 10$ que elucidam a representação $(x 3+x+1)+(x 2+4 x-2)$ $=-1+5 x+x 2(1+x)$, são as mesmas da tarefa t0, isto é, resolver: $(x 3+x+1)+(x 2+4 x-$ 2), que transformei na tarefa $t 1$, na qual considero os dois trinômios da tarefa t0, uma escrita polinomial de dois números no sistema de numeração decimal. Para isso, tomo $x=10$ e a tarefa t1 consistirá em: resolver: $(103+10+1)+(102+4.10-2)$. Para compor a tarefa t1, considerei a existência dialética ostensiva e não ostensiva entre o sistema de numeração decimal e a variável dos dois polinômios. Deste modo, estou propondo que a resposta da tarefa t0 é a mesma da tarefa t1, ou seja, $(103+10+1)+(102+4.10-2)=-1+5 x+x 2(1+$ $x)=-1+5.10+102 .(1+10)$.

Ressalto que, ao propor a manipulação ostensiva entre a variável $x$ e a base 10, estou concebendo uma técnica $\tau$, que consiste em manipular objetos ostensivos, vinculando aritmética à álgebra no tratamento das operações com polinômios.

Parte das ideias que expus nos dois parágrafos anteriores veio da minha compreensão da obra de Floriani (2000). Esse autor propôs ideias didáticas que associam a representação dos números do sistema de numeração decimal na escrita polinomial de potência de base dez. A partir dessa representação, ele iguala x a 10 e substitui o valor de 10 por $x$, tornando a escrita polinomial de potência de base dez em um polinômio na variável $x$.

Floriani (2000) também mostra a possibilidade de se aliar o algoritmo usual da soma, subtração, multiplicação e divisão aritmética ao ensino das operações com polinômios. Entretanto, Carvalho e Pereira (2009) esclarecem que há limitações para o que indica Floriani.

Após passarmos pela soma, subtração e multiplicação com polinômios, chegamos à divisão. Tentaremos aproximar a divisão de polinômios com a divisão usual ensinada dentro do sistema de numeração decimal indoarábico. Para tanto, precisamos ter certeza de que é possível fazer isso, pois algumas divisões de polinômios transcendem essa situação (CARVALHO; PEREIRA, 2009, p. 42).

A constatação de Carvalho e Pereira (2009) revela que a divisão de $6 x^{3}+6 x+4=6 x^{3}$ $+0 x^{2}+6 x+4 \operatorname{por} 1 x^{2}+2=7 x^{2}+0 x+2$, na forma dos números $N_{1}=6064$ e $N_{2}=102$ não são equivalentes, pois o quociente e o resto em ambos os casos diferem, ou seja, o quociente e o resto da divisão de $N_{1}$ por $N_{2}$ são, respectivamente, $59(5 x+9)$ e $46(4 x+6)$ e o quociente e o resto da divisão polinomial são, respectivamente, 6x (60) e -6x + $4(-56)$.

O tipo de tarefas (resolver a divisão polinomial) que Carvalho e Pereira (2009) recorreram para mostrar que a divisão polinomial nem sempre será possível, quando convertida em divisão numérica, por meio da escrita polinomial na potência de base dez, possui particularidades operatórias próprias da divisão polinomial, na qual a ostensividade e

\footnotetext{
${ }^{10}$ A palavra técnica é [...] usada como uma maneira de fazer uma tarefa, mas não é, necessariamente, como um procedimento estruturado e metódico ou algorítmico. [...] toda técnica exige, em princípio, uma justificativa, isto é, um "discurso lógico" (logos) que Ihe dá suporte, chamado de tecnologia, pois permite, ao mesmo tempo, encontrar o resultado e justificar que tal resultado está correto. Um conjunto de técnicas, de tecnologias e de teorias organizadas para um tipo de tarefa forma uma organização "praxeológica" (ALMOULOUD, 2007).
} 
a não ostensividade da divisão aritmética permite adaptar o uso do algoritmo euclidiano à técnica que soluciona esse tipo de tarefas. Porém, compreenda-se que o processo resolutivo desse tipo de tarefas mobiliza ostensividade e não ostensividade própria das estruturas algébricas polinomiais.

A monografia de Carvalho e Pereira (2009), obra principal que norteia este artigo, engloba elementos da Teoria Antropológica do Didático (TAD), concernentes aos objetos ostensivos e não ostensivos, tipos de tarefas $T_{i}$, técnicas $\tau$, tecnologia $\theta$ e teoria $\Theta$. É sobre esses elementos da TAD que abordamos na seção a seguir.

\section{Narrando Conexões entre Aritmética e Álgebra por intermédio da Teoria Antropológica do Didático}

A Teoria Antropológica do Didático (TAD) contempla elementos teóricos que me permite vislumbrar conexões entre aritmética e álgebra, articulando as operações aritméticas fundamentais no tratamento das operações polinomiais. Para isso, julgo relevante compreender os elementos que compõem o bloco $[T, \tau, \theta, \Theta]$, que designa uma praxeologia. Nesse bloco, temos:

- Tipo de tarefas T: uma tarefa $t_{2} \in \mathrm{T}$ é: representar o número racional inteiro 345 na forma de potência de base 10;

- Técnica $\tau$ : a técnica que resolve a tarefa $t_{2}$, é a representação de $\mathrm{N}=345=$ 3. $10^{2}+4.10^{1}+5$

- Tecnologia $\theta$ : a técnica $\tau$ é justificada na tecnologia de $N=$ $a_{2} \cdot 10^{2}+a_{1} \cdot 10^{1}+a_{0} \cdot 10^{0}=a_{2} a_{1} a_{0}$.

- Teoria $\Theta$ : elementos teóricos da Aritmética e Álgebra.

O bloco praxeológico $[T, \tau, \theta, \Theta]$ subdivide-se em dois, o bloco prático-técnico $[T, \tau]$ (do saber fazer ou da práxis) e o bloco tecnológico-teórico $[\theta, \Theta]$ (do saber ou do logos).

$\mathrm{Na} T A D$, compreendo que o bloco tecnológico-teórico $[\theta, \Theta]$, ou seja, o que contém a tecnologia $\theta$ e a teoria $\Theta$ possui dois elementos que podem revelar o grau de conhecimento matemático do professor de Matemática quando este estuda objetos matemáticos para elaborar ou reelaborar organizações matemáticas e didáticas ${ }^{11}$.

Se a técnica (ou as técnicas) que resolve (resolvem) determinados tipo de tarefas $T$ for assumida como um procedimento inicial que vislumbra facilitar a compreensão de certas noções matemáticas, como, por exemplo, as operações com polinômios na sétima série (oitavo ano) do Ensino Fundamental, então, devemos considerar o processo de ensino e aprendizagem dos conteúdos de Matemática nessa etapa da educação básica. Desse modo, a técnica $\tau$ que soluciona a tarefa $t_{0}$, resolver: $\left(x^{3}+x+1\right)+\left(x^{2}+4 x-2\right)$, pode ser idealizada por meio da tarefa $t_{1}$, resolver: $\left(10^{3}+10+1\right)+\left(10^{2}+4.10-2\right)$, em que se representa os polinômios $\left(x^{3}+x+1\right)$ e $\left(x^{2}+4 x-2\right)$ na escrita polinomial de base 10 , atribuindo-se à variável $x$ o valor 10 .

\footnotetext{
${ }^{11}$ [...] As organizações matemáticas referem-se à realidade matemática que se pode construir para ser desenvolvida em uma sala de aula e as organizações didáticas referem-se à maneira como se faz essa construção [...] (ALMOULOUD, 2007, p. 123).
} 
Assim, o que pretendo com os tipos de tarefas T é que elas me convenham como elemento de estudo para o desenvolvimento de uma organização praxeológica que associe a conexão entre aritmética e álgebra, em que o trabalho da técnica $\tau$ funcione por meio de tecnologias $\theta$ e em conformidade com a álgebra institucionalizada nas escolas de Ensino Fundamental.

Para Chevallard e Bosch (1999), a distinção entre técnica, tecnologia e teoria dependem do caráter funcional destas por meio do tipo de tarefas que são tomadas como referencial. Vejo isso imbricado na maneira como assumi ensinar a adição polinomial, tomando-se como referência o sistema de numeração decimal.

Um dos efeitos da tecnologia sobre a técnica é a modificação dessa técnica de forma que ela possa ampliar sua abrangência, ou ser sofisticada de modo que resulte em uma nova técnica (ALMOULOUD, 2007). Nesse sentido, as ideias de Floriani (2000), de associar o algoritmo usual da adição e da divisão aritmética para resolver adição e divisão de polinômios, tiveram como intuito, com certa limitação, propor uma técnica numéricoalgébrica para resolver adição, subtração, multiplicação e divisão de polinômios. O elemento tecnológico dessa técnica é considerar a variável no sistema de numeração decimal, na qual ela assume sempre o valor igual a dez, possibilitando transformar um polinômio em um número natural ou inteiro.

Lembremo-nos que, anteriormente, a tarefa $t_{0}$, resolver: $\left(x^{3}+x+1\right)+\left(x^{2}+4 x-2\right)$, foi transformada na tarefa $t_{1}$, resolver: $\left(10^{3}+10+1\right)+\left(10^{2}+4.10-2\right)$, desse modo, a tarefa to tem como solução: $-1+5 x+x^{2}(1+x)$. Essa solução é proposta por Chevallard e Bosch (1999). Ressalto, ainda, que a tarefa $t_{1}$ é uma consequência dos meus estudos da obra de Floriani (2000), que constam na monografia de Carvalho e Pereira (2009), da qual considerei tais ideias para representar os polinômios da tarefa to como sendo $10^{3}+10+1$ e $10^{2}+4.10-$ 2. Assim, a tarefa t recai em somar $1011(1000+10+1) \operatorname{com} 138(100+40-2=100+38)$. Procedo à soma de $1011 \mathrm{com} \mathrm{138,} \mathrm{que} \mathrm{resulta} \mathrm{1149.} \mathrm{Logo,} 1149$ na forma polinomial de potência de base dez, assume a escrita: $1.10^{3}+1 \cdot 10^{2}+4.10+9$. Em seguida, faço $x=10$ para transformá-lo em $1 \cdot x^{3}+1 \cdot x^{2}+4 \cdot x+9=x^{3}+x^{2}+4 x+9$. Portanto, a solução da tarefa to seria o polinômio $x^{3}+x^{2}+4 x+9$.

No confronto das soluções propostas para a tarefa to, a solução de Chevallard e Bosch (1999) é legítima, porque ela adveio da técnica de reduzir termos semelhantes. Logo, $x^{3}+x^{2}$ $+5 x-1$ é igual a $-1+5 x+x^{2}(1+x)$. Doutro modo, a resolução da tarefa to - resolver: $\left(x^{3}+x\right.$ $+1)+\left(x^{2}+4 x-2\right)-$ seguindo as ideias de Floriani (2000), que preconizam a técnica do cálculo dos valores numéricos dos polinômios $x^{3}+x+1$ e $x^{2}+4 x-2$, fazendo-se $x=10$, exige o trabalho dessa técnica por meio do algoritmo da soma aritmética. Porém, a tarefa to não se ajusta a essa técnica. Isso decorre do fato do polinômio $x^{2}+4 x-2$ possuir o coeficiente negativo menos dois ( -2$)$. Assim, esse coeficiente imprime uma mudança na técnica de Floriani (2000) para que ela se ajuste à técnica de Chevallard e Bosch (1999). Portanto, a solução que obtive para a tarefa $t_{0}$ por intermédio da tarefa $t_{1}$, na qual considerei os valores numéricos dos polinômios $x^{3}+x+1$ e $x^{2}+4 x-2$, ou seja, 1011 e 138, não está totalmente incorreta, mas não segue o mesmo trabalho da técnica de Chevallard e Bosch, que é a de reduzir termos semelhantes.

Contudo, quando recorri à técnica que consta na monografia de Carvalho e Pereira (2009), ou seja, pela escrita polinomial da potência de base dez, para resolver a tarefa $t_{1}$, encontrei a solução equivalente à de Chevallard e Bosch (1999). Desse modo, a técnica pela escrita polinomial na potência de base dez, quando aplicada na resolução da soma de dois 
polinômios, segue o mesmo trabalho da técnica que Chevallard e Bosch (1999) usaram para solucionar a tarefa $t_{0}$.

O pressuposto de Chevallard e Bosch definindo "tarefas, técnicas, tecnologias e teorias, foi para anunciarem a noção de organização praxeológica (ou praxeologia) pontual, regional ou global que são o conjunto de técnicas, tecnologias e teorias para as praxeologias pontuais" (COSTA, 2008, p. 19). Compreenda-se que organização praxeológica pontual, regional ou global, refere-se, respectivamente, à Organização Matemática Pontual, Regional ou Global.

Assim, um exemplo de uma Organização Matemática Pontual (OMP) é a tarefa: calcular $\mathrm{A}+\mathrm{B}$, em que $\mathrm{A}=2 x^{2}+x+2$ e $B=x^{2}+x+3$. Por conseguinte, se várias destas OMP puderem ser agrupadas por intermédio da tecnologia $\theta$, que justifica as técnicas $\tau$, resultantes da escrita polinomial na potência de base dez e estas técnicas $\tau$ são mobilizadas para resolver os tipos de tarefas T dessas OMP. Então, do agrupamento dessas várias OMP, surge uma Organização Matemática Local (OML). Essa OML é designada por Fonseca, Bosch e Gascón (2010) pela notação $\mathrm{OM}_{\theta}=[\mathrm{T} / \cdot / \cdot / \cdot$ ] . Da monografia de Carvalho e Pereira (2009, p. 38), extraí sete tarefas de uma atividade matemática, que constituem uma OML. Estas tarefas são:

- $t_{1}$ : Calcular $A+B$, onde $A=5 x^{3}+3 x^{2}+2 x+1$ e $B=4 x^{3}+5 x^{2}+7 x+2$;

- $t_{2}$ : Calcular $C+D$, onde $C=4 x^{2}+6 x+8$ e $D=7 x^{2}+4 x+3$;

- $t_{3}$ : Determinar $E-F$, sendo $E=9 x^{2}+8 x+7$ e $F=3 x^{2}+4 x+$;

- $t_{4}$ : Determinar $G-H$, sendo $G=5 x^{2}+4 x+2, H=x^{2}+8 x+4 ;$

- $t_{5}$ : Determinar $M \times N$, sendo $M=x^{2}+2 x+8$ e $N=x+2$;

- $t_{6}$ : Calcular $P \times Q$, onde $P=3 x^{2}+2 x+4$ e $Q=4 x^{2}+2$;

- $t_{7}$ : Determinar o quociente e o resto de $\mathrm{R}: \mathrm{S}$, onde $\mathrm{R}=\mathrm{x}^{3}+3 \mathrm{x}^{2}+7 \mathrm{x}+6$ e $\mathrm{S}$ $=x^{2}+2 x+4$

Essas sete tarefas foram resolvidas pela técnica $\tau$ que transforma os polinômios em números naturais e, em seguida, aplicam-se os algoritmos usuais da adição, subtração, multiplicação e divisão aritmética. Entretanto, durante o processo resolutivo dessas tarefas, o trabalho da técnica $\tau$ revelou a existência de elementos tecnológicos e teóricos, que não os percebi durante o estudo que fiz da obra de Floriani (2000) em relação ao ensino das operações com polinômios. A seguir, exponho sobre isso a partir da análise que fiz dos episódios que narram as minhas praxeologias como professor de Matemática.

\section{As Praxeologias Desenvolvidas a partir da Aplicação da Proposta Oriunda da Monografia de Especialização}

Aqui relato meus estudos e minha prática docente como parte de uma nova praxeologia. Nesse sentido, as praxeologias assumidas por mim antes do curso de especialização são partes estruturantes do meu Equipamento Praxeológico $(E P(X))^{12}$. Essas

\footnotetext{
12 [...] o conjunto de praxeologias que a pessoa dispõe, ou que está equipada (mesmo que não possa atualizar tal ou tal praxeologia que venha a ocupar tal posição dentro de tal instituição): é o que chamo de equipamento praxeológico da pessoa [...](CHEVALLARD, 2009, p. 1-2, tradução nossa, grifos nossos e no original).
} 
praxeologias se revelaram na minha prática docente em uma dinâmica cognitiva ${ }^{13}$ combinada ao EP $(X)$ que se remodelou durante o curso de especialização.

Nesse episódio, analisei a tarefa t: Dados os polinômios $A=-2 x^{4}-11 x^{3}-x^{2}+18 x+8 e$ $B=x^{2}+5 x+2$, determinar o quociente de $A$ por $B$. Essa tarefa possui objetos não ostensivos que começam a ser materializados ostensivamente no sétimo ano do Ensino Fundamental: representação dos números inteiros positivos e negativos, usando os sinais + e -; operações algébricas com números negativos e positivos $(-2-(-2),(+5) .(-2),(-2) \div(+1))$; regra de jogo de sinais do tipo $(+) .(-)=-,(-) \div(-)=+$, etc. Antes disso, predominam os algarismos indo-arábicos na composição posicional do sistema de numeração decimal e a extensão destes para os números naturais.

A aplicação da proposta didática em sala de aula rendeu alguns momentos inusitados que conflitaram o meu Universo Cognitivo $(\mathrm{UC}(\mathrm{x}))^{14}$ e modificaram o meu EP(x) para ensinar operações com polinômios. Esses momentos constam na monografia de Carvalho e Pereira (2009), e alguns deles são frutos das ideias dos próprios alunos que remodelaram a maneira de solucionar tipos de tarefas $T_{i}$ pela técnica $\tau$.

A proposta didática foi efetivada num total de 18 aulas, cada uma com duração de 90 minutos (CARVALHO; PEREIRA, 2009, p. 49). Dessas aulas, a aula 18 revelou que os alunos são capazes de solucionar tipo de tarefas $T$, propondo mudanças nas técnicas que recorremos para resolvê-las. Nessa aula, eu e a colega de pesquisa da monografia de Carvalho e Pereira (2009) propusemos aos alunos que resolvessem um exercício contendo vários tipos de tarefas T. Uma dessas tarefas era somar $5 x^{3}+3 x^{2}+2 x+7 \operatorname{com} 4 x^{3}+5 x^{2}+7 x$ +2 . Para essa tarefa, um aluno apresentou um processo resolutivo diferente dos outros alunos, ele usou um traçado retangular, semelhante ao do Quadro de Valor de Lugar (QVL), muito utilizado para ensinar a somar e subtrair nos anos iniciais do Ensino Fundamental. Este dispositivo recorre à noção não ostensiva de ordem que os algarismos indo-arábicos ocupam no sistema de numeração decimal e, assim, possibilita a manipulação ostensiva dos algarismos na adição e subtração aritmética. Eis a estratégia resolutiva do aluno:

$$
\begin{array}{lc|c|c|c|c}
x^{3}+3 x^{2}+2 x+1 & & 5 & 3 & 2 & 1 \\
4 x^{3}+5 x^{2}+7 x+2 & + & 4 & 5 & 7 & 2 \\
\hline & & 9 & +8 & +9 & +3
\end{array}=9 x^{3}+8 x^{2}+9 x+3
$$

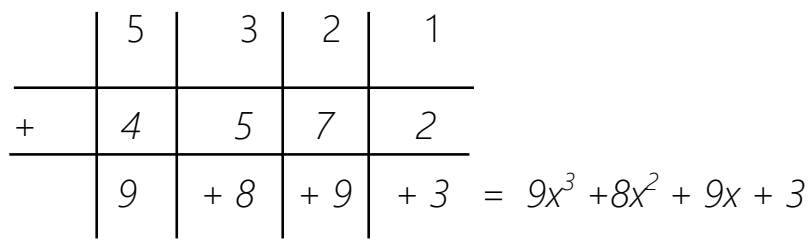

Se, para o aluno, teve sentido o que ele fez, para mim, significou alterações praxeológicas na proposta didática que elaborei, porque os outros alunos se interessaram pela maneira como ele resolveu essa tarefa. Implicitamente, esse aluno promoveu uma dinâmica cognitiva no meu universo cognitivo $(U(x))$, pois a técnica de calcular pelo QVL

\footnotetext{
${ }^{13}$ A dinâmica cognitiva envolve o processo de remodelação do equipamento praxeológico da pessoa, de forma que, "[...] alguns objetos desaparecem do universo cognitivo da pessoa, enquanto outros aparecem, e em correspondência há uma dinâmica praxeológica em que o equipamento praxeológico da pessoa muda, no sentido de que algumas partes deste equipamento perdem suas características de operação, enquanto outras partes são remodeladas e que novos elementos são adicionados ao longo do tempo" (MESQUITA, 2011, p. 13).

${ }^{14}$ Quando um objeto 0 existe para uma pessoa $x$, ou ainda que $x$ conhece 0 , a relação $R(x ; 0)$ especifica a maneira como $x$ conhece $o$. Chama-se, então, universo cognitivo de $x$ o conjunto $U C(x)=\{(0, R(x ; 0)) / R(x ; 0) \neq$ Ø) (CHEVALLARD, 2009, p. 6, tradução nossa, grifos nossos e no original).
} 
não fazia parte do meu equipamento praxeológico ou estava esquecida cognitivamente. No que tange a isso, Chevallard (2009) considera que na

[...] história da pessoa como sujeito, existe uma dinâmica cognitiva, que faz com que alguns objetos desapareçam de $(U(x)$ ), enquanto outros irão aparecer, e há uma dinâmica praxeológica pela qual o equipamento praxeológico de $x,[\ldots]$ muda - algumas partes desse equipamento perdem suas características de operação, enquanto outras partes são renovadas e novos elementos são adicionados ao longo do tempo [...] (CHEVALLARD, 2009, p. 6-7, tradução nossa).

Compreendo que a ideia do aluno é resultante do sistema de numeração decimal e dos algoritmos das operações aritméticas fundamentais, conforme exposto por Wechelun (1562), Carles (1927), Ifrah (1997a, 1997b) e Zuin (2005).

Fiz aqui um breve relato sobre minhas limitações no tratamento das operações aritméticas mediadas pela escrita polinomial na potência de base dez. $O$ meu universo cognitivo UC(x) estava limitado a uma compreensão algorítmica das operações aritméticas fundamentais em nível de Matemática escolar. Essa limitada compreensão proviera da não atualização do meu equipamento praxeológico EP(x).

Os reflexos das minhas sujeições institucionais refletiram no tratamento das operações aritméticas fundamentais, principalmente porque o processo tradicional compunha o meu EP(x). Esse processo é a modelação dominante na educação básica para se ensinar as operações aritméticas fundamentais de números naturais. Para superar as limitações do meu $\operatorname{EP}(X)$, tive que atualizá-lo, compreendendo a modelação do tratamento das operações aritméticas fundamentais por meio da escrita polinomial na potência de base dez.

Essa atualização se deu pela escrita polinomial na potência de base dez, associando-a a expressões algébricas, tomando-se $x=10$. Essa recorrência como processo de algebrização explicitam as classificações polinomiais que aparecem nos livros didáticos de Matemática do Ensino Fundamental: monômios, binômios, trinômios e polinômios (de quatro termos em diante). Assim, os números 20, 21, 125 e 3254 geram, respectivamente, $2.10^{1}+0.10^{0}=2 . x^{7}+0.10^{0}=2 x$ (monômio), $2.10^{1}+1.10^{0}=2 . x^{1}+7 . x^{0}=2 x+1$ (binômio), $1.10^{2}$ $+2.10^{2}+5 \cdot 10^{0}=7 \cdot x^{2}+2 \cdot x^{1}+5 \cdot x^{0}=x^{2}+2 x+5$ (trinômio) e $3 \cdot 10^{3}+2 \cdot 10^{2}+5 \cdot 10^{1}+4 \cdot 10^{0}=3 \cdot x^{3}$ $+2 \cdot x^{2}+5 \cdot x^{7}+4 \cdot x^{0}=3 x^{3}+2 x^{2}+5 x+4$ (polinômio).

\section{Considerações Finais}

Esta pesquisa foi motivada por meus estudos no Curso de Especialização em Educação Matemática. Esses estudos me permitiram estruturar uma proposta didática com uma praxeologia diferenciada para ensinar somar, subtrair, multiplicar e dividir polinômios. A partir disso, propus-me fazer uma análise das minhas praxeologias por intermédio das possíveis conexões entre aritmética e álgebra no contexto das minhas práticas docentes, desenvolvidas na sétima série (oitavo ano) do Ensino Fundamental.

Para desenvolver esta pesquisa, assumi a metodologia da pesquisa narrativa, com enfoque autobiográfico, porque se tratou de um estudo da minha pessoa como professor de Matemática no contexto do meu desenvolvimento profissional. Ressalto que a metodologia pensada para conduzir esta pesquisa passou por adequações ao longo dos procedimentos adotados para garantir, cientificamente, o estudo ora concluído. Entre estes 
procedimentos, cito o meu percurso de estudo das obras que tratam de Organizações Matemáticas (OM) e Organizações Didáticas (OD) sobre aritmética e álgebra, que garantiram um fluxo textual narrativo de acordo com as minhas intenções de pesquisa.

Entendo que o elo inicial da conexão entre aritmética e álgebra está na representação de números naturais na escrita polinomial de potência de base dez e uso desta representação no processo resolutivo das operações aritméticas fundamentais e das operações polinomiais. Essa constatação está descrita nas obras de Wechelun (1562), Carles (1927), Roxo et al. (1948), Crantz (1949), Floriani (2000), Eves (2004), Zuin (2005), De Maio (2009, 2011).

A partir da proposta didática da monografia de Carvalho e Pereira (2009) como uma organização praxeológica (ALMOULOUD, 2007), infiro que as influências praxeológicas assumidas por mim antes da graduação se tornaram parte do meu equipamento praxeológico EP (x) e ainda fazem parte dele. Entretanto, após o curso de graduação e de especialização, novos elementos praxeológicos conflitaram no meu universo cognitivo UC(x) e promoveram uma atualização do meu equipamento praxeológico (CHEVALLARD, 2009), mas não suficiente para corrigir as minhas incompreensões sobre certos objetos ostensivos e não ostensivos presentes tanto nas operações aritméticas quanto nas operações algébricas.

Enfatizo que as correções feitas por mim na proposta didática que elaborei remodelaram mais o meu $\mathrm{EP}(\mathrm{x})$. Porém, isso só foi possível por intermédio dos referenciais teóricos que embasam esta pesquisa, principalmente as obras que tratam dos sistemas de numeração, da escrita polinomial na potência de base dez e das que explicitam a lastro teórico da Teoria Antropológica do Didático.

Na perspectiva da Educação Matemática, esta pesquisa propõe um modelo epistemológico alternativo que visa a contribuir para o ensino das operações polinomiais no âmbito das instituições escolares. Além disso, traz esclarecimentos epistemológicos sobre alguns objetos ostensivos e não ostensivos que conduz a prática docente do professor de Matemática em sala de aula, principalmente, no que tange o processo de ensino e aprendizagem das operações polinomiais de somar, subtrair, multiplicar e dividir.

\section{Referências}

ABRAHÃO, Maria Helena Menna Barreto (Org.). A Aventura (auto)biográfica: teoria e empiria. Porto Alegre: EDIPUCRS, 2004.

ALMEIDA, Fernando Manuel Mendes de Brito. Sistemas de Numeração Precursores do

Sistema Indo-Árabe. Dissertação (Mestrado em Ensino da Matemática). Faculdade de Ciências da Universidade do Porto. Porto, 2007.

ALMOULOUD, Saddo Ag. Fundamentos da Didática da Matemática. Curitiba: Editora da UFPR, 2007.

ANDRADE, Roberto Carlos Dantas. A noção de tarefa fundamental como dispositivo didático para um percurso de formação de professores: o caso da geometria analítica. Tese (Doutorado em Educação em Ciências e Matemáticas). Universidade Federal do Pará, Instituto de Educação Matemática e Científica. Belém, 2012. 
ARAGÃO, Rosália M. R. de. Memórias de Formação e Docência: bases para pesquisa narrativa e biográfica. In: CHAVES, S. N.; BRITO, M. R. (Org.). Formação e Docência: perspectivas da pesquisa narrativa e autobiográfica. Belém: CEJUP, 2011.

AUSUBEL, D. P. NOVAK. J. D.; HANESIAN, H. Psicologia educacional. 2. ed. Rio de Janeiro: Interamericana, 1980.

BASTOS, M. H. C.; COLLA, A. L. A idealização do professor na representação da docência. Retratando mestres. In: ABRAHÃO, Maria Helena Menna Barreto (Org.). A Aventura (Auto)Biográfica: teoria e empiria. Porto Alegre: EDIPUCRS, 2004.

BOLEA CATALÁN, Pilar. El proceso de algebrización de organizaciones matemáticas escolares. Zaragoza: Prensas Universitarias de Zaragoza: Departamento de Matemática Aplicada, Universidad de Zaragoza, 2003. (Monografias del Seminário Matemático "Garcia de Galdeano", 29). Tesis - Universidad de Zaragoza.

BUENO, Belmira Oliveira. O método autobiográfico e os estudos com histórias de vida de professores: a questão da subjetividade. Revista Educação e Pesquisa, São Paulo, v.28, n.1, p. 11-30, jan./jun. 2002. Disponível em: <http://www.scielo.br/pdf/ep/v28n1/11653.pdf>. Acesso em: 31 mai. 2011

CARLES, D. José Dalmau. Aritmética Razonada y Nociones de Álgebra: Tratado Teórico Prático - Demostrado. 57a Edición, corregida y aumentada por D. José Maria Dalmau Casademont. Barcelona: Juan Darne, 1927. Madrid: Libreria y Casa Editorial, 1927. Gerona: Editores Dalmau Carles, Pla S. A., 1927.

CARVALHO, Cláudia Cristina Soares de. Uma análise praxeológica das tarefas de prova e demonstração em tópicos de álgebra abordados no primeiro ano do Ensino Médio. Dissertação (Mestrado em Educação Matemática). PUC/SP. São Paulo, 2007. Disponível em: $<$ http://www.pucsp.br/pos/edmat/ma/dissertacao/claudia cristina carvalho.pdf>. Acesso em: 29 mai. 2011.

CARVALHO, Cristiane C:; PEREIRA, José C. S. Aprendizagem significativa - das operações aritméticas às operações algébricas: o tratamento das operações algébricas a partir das operações aritméticas como conhecimento prévio. Monografia (Especialização em Educação Matemática). Núcleo de Pesquisa e Desenvolvimento da Educação Matemática e Científica da Universidade Federal do Pará. Belém, 2009.

CHEVALLARD, Yves. Le passage de l'arithmetique a l'algebrique dans l'enseignement des mathematiques au college - troisième partie - voies d'attaque et problemes didactiques. In: Petit $\quad x, \quad n^{0}$ 23, p. 05-38, 1990. Disponível em: < $\underline{\text { http://www-irem.ujf- }}$ grenoble.fr/spip/spip.php?rubrique25 >. Acesso em: 10 mai. 2014.

CHEVALLARD, Yves. Enseignement de l'algebre et transposition didactique. Rend. Sem. Mat. Univ. Pol. Torino. Vol. 52, n. 2, 1994. Disponível em: $<$ http://www.seminariomatematico.unito.it/rendiconti/cartaceo/52-2/175.pdf>. Acesso em: 09 mai. 2012.

CHEVALLARD, Yves. El análisis de las prácticas docentes en la teoria antropológica de lo didáctico. Recherches en Didactiques des Mathématiques, v. 19, n. 2, p. 221-266, 1999. Traducción de Ricardo Campos. Departamento de Didáctica de las Matemáticas. Universidad de Sevilla. Com la colaboración de Teresa Fernández García, Catedrática de 
Francés, IES Martinéz Montañes, Sevilla. Disponível em: < $\underline{\text { http://jose- }}$ desktop.uacm.edu.mx/nolineal/libros/campomedio/El analisis de las practicas docentes en la teoria antropologica de los didactico.pdf>. Acesso em: 18 abr. 2012.

CHEVALLARD, Yves. La TAD face au professeur de mathématiques. 2009. Disponível em: $<$ http://yves.chevallard.free.fr/spip/spip/article.php3?id article=162>. Acesso em: 24 abr. 2011.

CHEVALLARD, Yves; BOSCH, Marianna. La sensibilité de l'activité mathématique aux ostensifs. 1999. Disponível em: <http://yves.chevallard.free.fr/spip/spip/lMG/pdf/ Sensibilite aux ostensifs.pdf >. Acesso em: 24 abr. 2011.

COSTA, Mariza Canjirano da. Possibilidades de articulação dos ostensivos e não ostensivos no ensino da noção de sistemas de duas equações lineares a duas incógnitas. Dissertação (Mestrado em Educação Matemática). UNIBAN/SP. São Paulo, 2008. Disponível em: $<$ http://www.uniban.br/pos/educamat/pdfs/teses/Mariza\%20Canjirano\%20da\%20Costa.pdf

>. Acesso em: 03 mai. 2011.

CRANTZ, Paul. Manuales Técnicos Labor No 2: Aritmética y Álgebra. Versión de la Duodécima Edición Alemana por David Soler Carreras. Barcelona, Madrid, Buenos Aires, Rio de Janeiro: Editorial Labor S. A., 1949.

CRUZ, Eliana da Silva. A Noção de Variável em Livros Didáticos de Ensino Fundamental: um estudo sob a ótica da organização praxeológica. Dissertação (Mestrado em Educação Matemática). PUC/SP. São Paulo, 2005. Disponível em: $<$ http://www.sapientia.pucsp.br/tde busca/index.php?tipoPesquisa=1>. Acesso em: 01 mai. 2011.

DE MAIO, Waldemar. Álgebra: estruturas algébricas básicas e fundamentos da teoria dos números. Rio de Janeiro: LTC, 2011. ( Fundamentos de matemática; 16).

DE MAIO, Waldemar. Álgebra: estruturas algébricas e matemática discreta. Rio de Janeiro: LTC, 2009. ( Fundamentos de matemática).

DELGADO,Tomás Ángel Sierra. Lo Matemático en el Diseño y Analisis de Organizaciones Didácticas: los sistemas de numeración y la medida de magnitudes. Memoria para optar al Grado de Doctor. Universidad Complutense de Madrid, Facultad de Educación, Departamento de Didáctica y Organización Escolar. Madrid, 2006.

EVES, Howard. Introdução à história da matemática. Tradução Hygino H. Domingos. Campinas, SP: Editora da UNICAMP, 2004.

FLORIANI, José Valdir. Professor e pesquisador: exemplificação apoiada na matemática. 2. ed. Blumenau: Ed. da FURB, 2000.

FONSECA, C.; BOSCH, M.; GASCÓN, J. El momento del trabajo de la técnica en la completación de organizaciones matemáticas: el caso de la "regla de Ruffini". s/d. Disponível em: <http://www4.ujaen.es/ aestepa/TAD/Comunicaciones/Fonseca Bosch Gascon.pdf>. Acesso em: 08 abr. 2012.

FREITAS, M. T. M.; FIORENTINI, D. As possibilidades formativas e investigativas da narrativa em educação matemática. Horizontes, Revista Semestral do Programa de Pós-Graduação Stricto Sensu em Educação da Universidade São Francisco. v. 25, n. 1, p. 63-71, jan./jun. 2007. 
Disponível em: $\quad<\underline{\text { http://www.saofrancisco.edu.br/itatiba/mestrado/educacao/ }}$ uploadAddress/edicao completa\%5B11019\%5D.pdf\#page=63>. Acesso em: 01 jun. 2011.

GALVÃO, Maria Elisa Esteves Lopes. História da Matemática: dos números à geometria. Osasco: Edifieo, 2008. (Coleção Texto).

GONÇALVES, Terezinha Valin Oliver. A pesquisa Narrativa e a Formação de Professores: reflexões sobre uma prática formadora. In: CHAVES, S. N.; BRITO, M. R. (Org.). Formação e Docência: perspectivas da pesquisa narrativa e autobiográfica. Belém: CEJUP, 2011.

IFRAH, Georges. História universal dos algarismos, volume 1: a inteligência dos homens contada pelos números e pelo cálculo. Tradução Alberto Muñoz e Ana Beatriz Katinsky. Rio de Janeiro: Nova Fronteira, 1997a.

IFRAH, Georges. História universal dos algarismos, volume 2: a inteligência dos homens contada pelos números e pelo cálculo. Tradução Alberto Muñoz e Ana Beatriz Katinsky. Rio de Janeiro: Nova Fronteira, 1997b.

IFRAH, Georges. Os números: a história de uma grande invenção. Tradução Stella Maria de Freitas. rev. téc. Antônio José Lopes, Jorge José de Oliveira 11. ed. São Paulo: Globo, 2005.

KEPPKE, Charston Lima. Álgebra nos Currículos do Ensino Fundamental. Dissertação (Mestrado Profissional no Ensino de Matemática). PUC/SP. São Paulo, 2007.

MESQUITA, Flávio Nazareno Araújo. As dinâmicas praxeológicas e cognitivas e a construção do conhecimento didático do professor de matemática. Dissertação (Mestrado Acadêmico). Universidade Federal do Pará, Instituto de Educação Matemática e Científica. Belém, 2011.

PEREIRA, José Carlos de Souza. Análise Praxeológica de Conexões entre Aritmética e Álgebra no Contexto do Desenvolvimento Profissional do Professor de Matemática. Dissertação (Mestrado). Universidade Federal do Pará, Instituto de Educação Matemática e Científica, Programa de Pós-Graduação em Educação em Ciências e Matemáticas. Belém, 2012.

RAMPAZZO, Lino. Metodologia científica: para alunos dos cursos de graduação e pósgraduação. 2. ed. São Paulo: Loyola, 2002.

ROXO, E.; CUNHA, H. L.; PEIXOTO, R.; NETTO, C. D. Matemática - $2^{\circ}$ Ciclo - $1^{\text {a }}$ Série. 4. ed. Rio de Janeiro: Livraria Francisco Alves, 1948.

SAVELI, Esméria De Lourdes. Narrativas Autobiográficas de Professores: um caminho para a compreensão do processo de formação. Revista Práxis Educativa. Ponta Grossa, PR, v. 1, n. 1, p. 94-105, jan./jun. 2006. Disponível em: <http://www.eventos.uepg.br/ ojs2/index.php/praxiseducativa/article/view/354/362>. Acesso em: 31 mai. 2011.

SEVERINO, Antônio Joaquim. Metodologia do trabalho científico. 23. ed. rev. atual. São Paulo: Cortez, 2007.

SILVA, Maria José Ferreira da. Investigando saberes de professores do Ensino Fundamental com enfoque em números fracionários. Tese (Doutorado em Educação Matemática). PUC/SP. São Paulo, 2005. Disponível em: <http://www4.pucsp.br/pos/edmat/ do/tese/maria_jose_ferreira_silva.pdf> . Acesso em: 05 abr. 2012.

SOUSA, Adilson Sebastião de. Metacognição e Ensino de Álgebra: análise do que pensam e 
dizem professores de matemática da educação básica. Dissertação (Mestrado em Educação). Universidade de São Paulo, Faculdade de Educação. São Paulo, 2007. Disponível em: <http://www.teses.usp.br/teses/disponiveis/48/48134/tde-29012009-120830/pt-br.php> Acesso em: 14 jun. 2011.

USISKIN, Zalman. Concepções sobre a álgebra da escola média e utilizações das variáveis. In: COXFORD, A. F.; SHULTE, A. P. As Ideias da Álgebra. Trad. Hygino H. Domingues. São Paulo: Atual, 1995.

ZUIN, Elenice de Souza Lodron. Somar, subtrair, multiplicar e dividir números inteiros: o método analítico na Arithmetica Raciocinada de Pedro d'Alcantara Lisboa, publicada em 1863. Revista Educação em Questão. Natal, v. 23, n. 9, p. 31-52, mai. /ago. 2005. Disponível em: <http://www.revistaeduquestao.educ.ufrn.br/pdfs/v23n09.pdf>. Acesso em: 25 mar. 2012.

WECHELUM, Andrean. Arithmética. 1562. Cum Privilegio Regis. Disponível em: <http://fondosdigitales.us.es/fondos/libros/985/10/arithmetica/> Acesso em: 09 set. 2011. 